\title{
FОTO

\section{Cineastas españoles del cambio de siglo en la órbita de la ciencia ficción}

\section{Spanish Filmmakers of the Change of Century in the Orbit of Science-Fiction Genre}

\author{
Débora Madrid \\ Universidad Autónoma de Madrid, España \\ dboramb@gmail.com \\ https://orcid.org/o000-0003-1950-7103
}

\section{Resumen:}

En la renovación del cine español a partir de la década de 1990 tiene un papel crucial, ampliamente señalado en las historias recientes del cine español, el recurso a los géneros cinematográficos como fórmula narrativa. En este contexto la ciencia ficción, uno de los casos aún por estudiar en profundidad, se ha ido haciendo cada vez más presente en la producción cinematográfica española. En este artículo proponemos un repaso por las principales aportaciones españolas al género en el periodo de finales del siglo XX y primeras décadas del XXI, prestando atención a cómo los cineastas del momento han contribuido, también desde la ciencia ficción, ha desdibujar la frontera que tradicionalmente ha separado el cine de géneros y el cine de autor o contrapuesto el cine lo géneros a la identidad nacional de nuestro cine.

\begin{abstract}
:
In the renewal of Spanish cinema from the 1990s onwards, as recent histories of Spanish cinema has pointed out, genre as narrative formula has played a crucial role. In this context, science fiction, one of the cases yet to be studied in depth, has become increasingly present in Spanish film production. In this paper we propose an overview of the main Spanish contributions to the genre in the period of the late twentieth century and the first decades of the twenty-first; paying special attention to how the filmmakers of the moment have contributed, also from science fiction, to blur the border that traditionally has separated genre films and the auteur cinema or that has opposed genres to the national identity of our cinema.
\end{abstract}

Palabras clave: cine español; cine de ciencia ficción; géneros cinematográficos; autoría.

Keywords: Spanish cinema; science-fiction films; film genre; authorship. 


\section{Introducción}

La renovación del cine español a partir de la década de 1990 con la irrupción de un nutrido grupo de directores y directoras cuyos trabajos se desmarcaban de la generación anterior, supuso la adopción de nuevas fórmulas, intereses y referencias. Destaca la recurrencia a los géneros cinematográficos, predominantes en el cine estadounidense y que fueron uno de los recursos narrativos de los que echaron mano buena parte de estos y estas jóvenes cineastas, utilizándolos como una herramienta narrativa clave, marcando el camino a generaciones posteriores y transformando el panorama de la industria cinematográfica nacional (Rodríguez Ortega, 2020). Entre ellos, la ciencia ficción ha sido uno de los que menos atención ha suscitado desde el ámbito académico. En primer lugar, por la escasa consideración que la crítica ha mantenido hacia el cine de géneros en su conjunto frente a propuestas consideradas más intelectuales, experimentales o autorales (Madrid, 2019, pp.35-42). En segundo lugar, porque, ciertamente, no ha sido uno de los géneros más practicados por la producción cinematográfica española, en comparación con otros como el cine policiaco o el terror.

Un primer objetivo de este artículo es, precisamente, poner en evidencia dos grandes prejuicios que críticos/as e historiadores/as han manifestado a la hora de considerar el cine de géneros (y especialmente la ciencia ficción): una dicotomía entre los conceptos de cine autoral y comercial y otra entre las ideas de cine de géneros y cine con identidad nacional. Expondremos estas ideas en un breve apartado teórico que nos permitirá, desde el punto de vista metodológico, adoptar el concepto de transnacionalidad como base para la superación de dichos prejuicios. Ello nos permitirá, a lo largo del texto, llevar a cabo nuestro segundo objetivo: describir el desarrollo de la ciencia ficción en el cine español del cambio del siglo XX al XXI a partir de un corpus cinematográfico coherente con la eliminación de las barreras de esas dos dicotomías mencionadas (incluyendo películas dirigidas por cineastas no nacidos en España, producidas fuera de España, que imitan éxitos comerciales del género o que utilizan la ciencia ficción para construir historias 
completamente personales; por poner algunos ejemplos). En consecuencia, repasaremos la producción cinematográfica española no únicamente a partir de los grandes temas de la ciencia ficción, sino que también estableceremos relaciones entre ellas en lo que respecta a aspectos conectados con su producción, su identidad nacional/transnacional, su autoría, etc.

Al mismo tiempo, se observará, a lo largo del artículo en su conjunto, cómo la ciencia ficción se ha ido haciendo cada vez más presente en la cinematografía española, especialmente a partir de los años noventa. Veremos cómo su práctica ha formado parte de la hibridación de estilos y géneros que el cine español ha vivido en el cambio del siglo XX al XXI, de su mirada a referencias foráneas en cuanto a los temas a tratar o de sus aspiraciones de internacionalización en el aspecto comercial.

\section{La generación de los noventa y los géneros como síntoma de transnacionalidad}

Este trabajo se sitúa en un marco en el que se plantean diversas cuestiones teóricas relevantes. En primer lugar, destacamos cómo, pese la reiteración de la renovación cinematográfica que supone en el ámbito español la nueva generación de la década de 1990, se han seguido manteniendo, especialmente por parte de críticos/as e historiadores/as, ciertos presupuestos que han limitado una comprensión de la obra de algunos de estos cineastas en toda su complejidad. Nos referimos, concretamente, a la polarización crítica entre los conceptos de cine de autor y cine de géneros. Una dicotomía heredera de la influyente teoría de autor francesa de mediados del siglo XX y que llevó durante décadas a infravalorar a los géneros cinematográficos frente a propuestas de carácter más autoral o de un marcado componente realista ${ }^{1}$, llevando a utilizar el concepto de género como un calificativo peyorativo:

\footnotetext{
1 Mucho tuvieron que ver, en este sentido, las conclusiones de las Conversaciones de Salamanca de 1955 que apostaban ya por un rechazo al modelo del cine americano en favor de un cine de personalidad nacional basado en el realismo - y que tenía como referente el neorrealismo italiano- (Benet, 2012, p. 274). Al mismo tiempo, con la llegada al poder del PSOE y las políticas cinematográficas del decreto de 1983, inspirado por Pilar Miró, se facilitó
} 
the relationship between genre and auteurism in cinema has been historically tempestuous. To discuss the friction between the two it is useful to parse de difference between genre as a classificatory label and "genre film" as a pejorative used to describe formulaic filmmaking. [...] in Spanish cinema history, the view of genre has almost exclusively been constructed negatively, often as a reaction against the functional definitions of genres adopted from American and European cinemas (Beck y Rodríguez Ortega, 2008, p. 5).

Dicha polarización entre autoría y géneros llevó a algunos los críticos a enfrentar, a partir de los años noventa, verdaderos escollos terminológicos a la hora de tratar de etiquetar un cine renovador que, precisamente, venía a desintegrar ese esquema con obras que interconectaban hábilmente los modelos genéricos y las aspiraciones comerciales con propuestas enormemente personales. Un ejemplo evidente es la clasificación de Monterde, quien establece una división entre "cine mimético" (refiriéndose a la recurrencia a los géneros hollywoodienses), "cine de consumo interno" y “cine de autor". Sin embargo, en la última de las categorías se ve obligado a conciliar las propuestas autorales con la visión comercial, utilizando conceptos ambiguos como "autoría netamente industrial”, "internacionalismo autoral", “autoría moderna" o "autoría industrial internacional” (Monterde, 2006, p. 53-57). Del mismo problema parten las entrevistas que realiza Heredero a los nuevos directores y directoras de los noventa, cuyas preguntas evidencian la dificultad que la crítica del momento seguía teniendo para salirse, en sus análisis, de las presunciones que dividen la producción cinematográfica entre cine autoral y cine comercial:

$Y$ si tanto te interesa el fondo de lo que cuentan las películas, ¿Cómo explicas tu admiración por Spielberg? [...] ¿̇crees que se puede hacer cine de género $y$, al mismo tiempo cine de autor?

Para mí el cine de Spielberg es cine de autor. Con sólo ver dos planos de cualquiera de sus películas se las puede identificar. Y eso es lo que hay que

\footnotetext{
la financiación de proyectos de especial interés, de nuevos realizadores o de carácter experimental (ver Pérez Moran y Pérez Millán, 2017). Un sistema de inversión que "acabó con los filmes de bajo presupuesto y rédito inmediato típicos de finales de los setenta" (Benet, 2012, p. 396), con lo que la práctica del cine de géneros se vio nuevamente mermada.
} 
conseguir: no traicionar lo personal con lo comercial. El reto consiste en que los espectadores hagan suyas tus obsesiones, que entren en ese mundo creado por tus imágenes. Alejandro Amenábar (Heredero, 1997, p. 84 y 98).

Tal vez sea esa necesidad de haceros entender la que os lleva utilizar los moldes del cine de género, más asequibles para el público, como elementos narrativos de películas que luego acaban siendo evidentemente "de autor"...

[...] A veces parece que se sigue utilizando la ecuación "comercialidad masiva igual a estupidez, interés minoritario igual a calidad". Todos sabemos, en cambio, que esto no puede convertirse en una regla de oro, porque hay películas muy originales y minoritarias que son una estupidez y otras muy comerciales que son maravillosas, y también al revés en ambos casos. [...] Lo curioso es que, casi sin darnos cuenta, hemos pasado de denostar el cine de Spielberg por su comercialidad a valorarlo, ahora, por el hecho constatable de que le gusta a la gente. $Y$ esto no es algo misterioso, pero, en cambio nadie lo estudia. Se estudia por qué funciona el cine de Eisenstein, todo el mundo ha visto mil veces la puta bajada de las escaleras y ha dicho: “iQué importante!”, pero lo que se considera frívolo nadie lo analiza. El entretenimiento se achaca a un sentimiento mágico de bienestar, pero nadie sabe muy bien por qué el cine de Frank Capra sigue conectando con la mayoría de la gente. Capra no es maravilloso porque sí, sino por una serie de razones concretas. Álex de la Iglesia (en Heredero, 1997, p. 463.464) ${ }^{2}$.

Respuestas como las que aquí dan Amenábar y Álex de la Iglesia evidencian su deseo de superar la inoperatividad de la división entre lo comercial y lo autoral. Estudios posteriores, quizás aventajados por la observación un poco más distante de las películas de la década de 1990, han ido cuestionando esa dicotomía cine autoral-cine de géneros/comercial. De hecho, se ha continuado incidiendo en la comprensión de la etiqueta de autor/autora más como un recurso de promoción nacional e internacional que como una opción creativa

\footnotetext{
2 Aunque directores como Amenábar o de la Iglesia manifiestan claramente esta opinión, hay que señalar que no todos tenían tan claro ese cuestionamiento de la contraposición cine de géneros-cine de autor; así se evidencia en las entrevistas que Heredero hace a Daniel Calparsoro (1997, p. 260), Isabel Coixet (1997, p. 301) o Agustín Díaz Yanes (1997, p. 343).
} 
frente al cine de géneros (Triana-Toribio, 2008; Camporesi, 2011, p. 88). En este sentido,

Los representantes de la joven generación de los noventa del siglo XX aceptan la dimensión económica del cine como un reto, no como una contradicción al estatus del autor, lo cual no impide que el cine español actual y sus críticos sigan rindiendo un culto al auteur. (Pohl y Türschmann, 2007, p. 17).

En segundo lugar, queremos llamar la atención sobre una segunda confrontación históricamente presente en la crítica del cine español, aquella que contrapone los géneros cinematográficos a la existencia de un cine de identidad nacional. El modelo de producción industrial hollywoodiense ha suscitado considerar el uso de los géneros cinematográficos como una americanización del cine español, lo que ha insistido en la infravaloración del cine de géneros en España. En esta línea, la aproximación de muchas películas a los modelos provenientes de Hollywood, parece una intromisión o desvirtuación de los temas o preocupaciones que se valoran como propios, "resultando con ello extraños híbridos derivados del intento de españolizar esos géneros" (Monterde, 1995, p. 230-231). Una hibridación que, como parece desprenderse de la cita de Monterde, no siempre es bien considerada y que historiadores como Heredero manifiestan como una dificultad a la hora de establecer una taxonomía adecuada para su estudio (1993, p. 163). Han sido los estudios anglosajones los que han destacado la necesidad de analizar el cine español de este periodo en un marco que trascienda las fronteras nacionales y lo comprenda como fruto de las tensiones no solo entre lo autoral y lo comercial sino también entre lo local y lo global. De esta manera, el uso de los géneros no tiene por qué ser entendido exclusivamente como una "americanización", sino como una producción de carácter "transnacional" (Kinder, 1993; Beck y Rodríguez Ortega, 2008; Labanyi y Pavlović, 2013; Oliete-Aldea, Oria y Tarancón, 2016), entendiendo esta transnacionalidad como el conjunto de elementos que dificultan una adscripción nacional exclusivista de las producciones: coproducción entre diversos países, diversidad nacional de los equipos técnicos y artísticos, elementos culturales o modelos narrativos que se toman de otros referentes internacionales o que, 
aun formando parte del acervo de una país, trascienden las fronteras o son parte de culturas más amplias como la Europea, etc. Es por ello por lo que nos posicionamos junto a esa necesidad de hacer análisis de carácter transnacional, tanto en lo relativo a la industria cinematográfica (la producción, la distribución y la recepción pueden abarcar un mercado global); como en cuestiones narrativas, temáticas o de interpretación cultural (que pueden partir de múltiples referencias internas o externas). De hecho, los textos españoles más recientes recogen dichos planteamientos e insisten, precisamente, en cómo el cine de las últimas décadas ha traído "una mayor globalización y ha desdibujado el concepto de cines nacionales" (Sánchez Noriega, 2020, p. 9)3.

Finalmente, las ideas expuestas nos llevan a considerar también el propio concepto de género cinematográfico en ese mismo contexto transnacional. Siguiendo la línea teórica de Rick Altman (2000) - que ha sido ya aplicada al cine español de géneros de la década de los noventa (Huerta, 2005)-, entendemos los géneros cinematográficos no como categorías de clasificación fijas externas a las películas, sino como herramientas discursivas que son utilizadas por los distintos usuarios de las mismas (cineastas, críticos, público...). La aproximación pragmática de Altman ofrece un nuevo argumento para cuestionar la confrontación entre moldes genéricos y cines nacionales:

Construido sobre una paradoja fundamental, el género subsiste porque parece que ofrece un firme anclaje en un sustrato transnacional y transhistórico que ignora los caprichos del espacio y el tiempo. Sin embargo, quienes ponen en sus bocas términos genéricos e invocan categorías genéricas lo hacen de un modo tan contradictorio que acaban impidiendo cualquier posible asociación entre conceptos como permanencia, universalidad y la noción de género. (Altman, 2000, p. 259).

En consecuencia, comprendemos el género como un recurso creativo más para los cineastas, "una mera plataforma para la creatividad y la innovación” (Stam,

3 Para una visión panorámica sobre el cine español de las últimas décadas del siglo XX ver también Sánchez Noriega (2019). 
2001, p. 154) y, al mismo tiempo, como una estructura privilegiada en la que se materializa todo el proceso de "cross-fertilization" (Oliete-Aldea, Oria y Tarancón, 2016, p. 6) entre la industria cinematográfica española y otros cines a nivel internacional, entre los que la cinematografía de Hollywood es una de las influencias más significativas. Entendemos pues, el cine español de finales del siglo XX y primeras décadas del XXI en este contexto, restando importancia a las aparentes contradicciones entre lo autoral y lo comercial o entre el uso de los géneros y la nacionalidad de las películas; y valorando más conscientemente su condición transnacional. Es, en definitiva, en este marco, en el que situamos las aproximaciones del cine español a la ciencia ficción: en convivencia con propuestas netamente autorales, en conexión con tendencias o temas frecuentes en el ámbito internacional más comercial o en un marco de estrategias de coproducción que sobrepasan los conceptos estrictos de nacionalidad.

\section{La ciencia ficción en el cine español del cambio de siglo: nuevos cineastas y modos de producción.}

La ciencia ficción no es uno de los géneros más representativos y practicados del cine español. No obstante, si observamos sus principales ejes narrativos podemos rastrear ejemplos de los mismos más o menos presentes en la producción española a partir de la década de 19604. Estos ejes narrativos son, a grandes rasgos: 1) la exploración de otros mundos y otros tiempos y 2) las transformaciones individuales, sociales y culturales producidas por la ciencia y la tecnología (Telotte, 2002, p. 21). En el primero de los casos podemos citar ejemplos como Llegaron los marcianos (Franco Castellano y Giuseppe Moccia, 1965), Órbita mortal (Primo Zeglio, 1968), La ciudad sin hombres (Jesús Franco, 1971), El refugio del miedo (José Ulloa, 1974), El hombre perseguido por un OVNI (Juan Carlos Olaria, 1976), Viaje al centro de la Tierra (Juan Piquer Simón, 1977), Si las mujeres mandaran o mandasen (José María Palacio, 1982) o El caballero del dragón (Fernando Colomo,

4 Salvando algún caso previo aislado como Madrid en el año 2000 (Manuel Noriega, 1925). 
1985), entre otros. En el segundo grupo podemos situar Gritos en la noche (Jesús Franco, 1962), Miss muerte (Jesús Franco, 1966), Trasplante de un cerebro (Juan Logar, 1970), Odio mi cuerpo (León Klimovsky, 1974), Largo retorno (Pedro Lazaga, 1975), Memoria (Francisco Macián, 1977) o El vivo retrato (Mario Menéndez, 1987), entre otros5.

A partir de la década de 1990, los ejemplos se multiplican. Suele reiterarse, como característica de los y las cineastas debutantes en este periodo, precisamente, la recurrencia a modelos genéricos más comerciales a nivel internacional. En este sentido, cabe destacar dos figuras que desde el principio apostaron claramente por el cine de género y que muy rápidamente se consolidarán como modelos a imitar para otros cineastas. Son los casos de Álex de la Iglesia y Alejandro Amenábar6. Ambos recurren a la ciencia ficción al inicio de sus carreras, con Acción Mutante (1992) y Abre los ojos (1996) respectivamente. Pese a que, como hemos señalado, existían ejemplos de ciencia ficción con anterioridad, la repercusión de estas dos películas abrirá la puerta a la posibilidad de producir ciencia ficción en España sin que ello trajera aparejado de manera directa el fracaso económico7. En concreto, la opera prima de Álex de la Iglesia desafió

algunas de las inercias más significativas en las que el género parecía instalado, la más importante de ellas la que negaba a la ciencia ficción hecha en España la posibilidad de integrar fuentes procedentes de la cultura popular local (los cómics de Bruguera, por ejemplo, pero también el cine explotation europeo representado aquí por Jesús Franco y la mirada torva a la sociedad fuertemente jerarquizada del cine berlanguiano) en un discurso temático inherente al contexto sociocultural en el que la película es concebida (en términos estrictos, el film relata nada menos que las desventuras de una banda

\footnotetext{
5 Para un repaso más exhaustivo de la historia del género en el cine español ver Madrid (2019). ${ }^{6}$ Son, de hecho, dos de los cineastas de su generación más estudiados desde sus inicios (Rodríguez Marchante, 2002; Sempere, 2004; Berthier, 2007; Buse, Triana-Toribio y Willis, 2007; Angulo y Santamarina, 2012; entre otros).

7 Así había sucedido en las décadas previas, donde la ciencia ficción era objeto generalmente de producciones de bajo presupuesto o, en caso contrario, como sucedió con El caballero del dragón, habían supuesto un despilfarro de grandes proporciones.
} 
terrorista intergaláctica de inequívoca raigambre vasca). (Sánchez Trigos, 2018, p. 313).

Muy pronto la huella de Acción Mutante se dejó ver en otras producciones como Supernova (Juan Miñón, 1993), Atolladero (Óscar Áibar, 1995) o La mujer más fea del mundo (Miguel Bardem, 1999). Como en Acción Mutante, en la mayoría de estas películas el motivo de ciencia ficción queda prácticamente en segundo plano frente a ese humor paródico entre el costumbrismo y el cómic. Por su parte, Alejandro Amenábar contribuyó también a abrir el camino a futuras producciones de ciencia ficción, siendo Abre los ojos un modelo evidente, por ejemplo, para Somne (Isidro Ortiz, 2005); que no solo imita su compleja estructura narrativa basada en flashbacks y la pérdida de memoria del personaje principal debido a la conexión de su cerebro a un sistema cibernético, sino que recurre incluso a Chete Lera, uno de los actores principales del filme de Amenábar.

Otra de las novedades frecuentemente señaladas a partir de la generación de los noventa es el aumento de mujeres directoras. En esta línea, hay que destacar el caso de María Lidón (María Luna), que, como había hecho ya Álex de la Iglesia, debuta en el largometraje con una película de ciencia ficción: Stranded: náufragos (2001). Es significativo mencionar que no son casos aislados y que otros cineastas de finales del siglo XX y comienzos del XXI apostarán por estrenarse con obras de ciencia ficción, como así hacen Óscar Áibar con Atolladero; Javier Fesser con El milagro de P. Tinto (1998); Nacho Vigalondo con Los cronocrímenes (2007), F. Javier Gutiérrez con Tres días (2008) o Kike Maíllo con Eva (2011).

Si pensamos en términos de nacionalidad, es evidente que muchas de estas películas presentan un fuerte vínculo con la cultura nacional y local española. Hemos mencionado ya la relación de Acción Mutante con el País Vasco, una película protagonizada por una banda terrorista que sin duda es un remedo de E.T.A. Pero también está muy presente un costumbrismo más rural, familiar y religioso en El milagro de P. Tinto; donde además se lleva a la pantalla el humor colorido y luminoso de los tebeos de Bruguera. Encontramos también 
filmes rodados en otras lenguas nacionales como el catalán en el caso de Científicamente perfectos (Francesc Capell, 1997) o L'altra frontera (Andre Cruz Shiraiwa, 2014); e incluso localizaciones muy reconocibles para el público español como el Madrid de Abre los ojos o Extraterrestre (Nacho Vigalondo, 2010) y la Barcelona de Los últimos días (Álex y David Pastor, 2013) junto a otras menos reconocibles pero explícitamente señaladas como la Toledo de La piel que habito (Pedro Almodóvar, 2011). No obstante, el carácter transnacional es cada vez más perceptible en el cine español a partir de los años noventa. La propia recurrencia a modelos narrativos de géneros es síntoma de una mirada al exterior, a ese cine estadounidense que es referencia confesa para los cineastas de la generación y que se considera también como una oportunidad para conquistar las taquillas fuera de España. Un éxito evidente en este sentido (es decir, de reconocimiento exterior) fue sin duda la compra de los derechos de Abre los ojos por parte de Tom Cruise para la realización del remake Vanilla Sky (Cameron Crowe, 2001).

En otros casos, la estrategia de la coproducción subraya el deseo de internacionalización. Durante la última década del siglo XX y las primeras del XXI se llevarán a cabo numerosas películas de ciencia ficción en coproducción entre España y otros países. Con Francia en el caso de Acción Mutante, La ciudad de los niños perdidos (Marc Caro, Jean Pierre Jeunet, 1995), Amazone (Philipe de Broca, 2000), La posibilidad de una isla (Michael Houellebecq, 2009), Eva o Los últimos días. Con Inglaterra en producciones como Nexus 2431 (José María Forqué, 1994), Planet 51 (Jorge Blanco, Javier Abad, Marcos Martínez, 2009) o Segundo Origen (Carles Porta, 2016). Y en otras ocasiones Italia en Abre los ojos, Canadá en P3K: Pinocho 3000 (Daniel Robichaud, 2004), Bulgaria en Autómata (Gabe Ibáñez, 2014), Estados Unidos en Atrapa la bandera (Enrique Gato, 2015), Bélgica en Evolution (Lucile Hadzihalilovic, 2015) o Suecia en Vulcania (José Skaf, 2015). En el ámbito latinoamericano hay también algunas colaboraciones: con Perú en El forastero (Federico García Urtado, 2002), con Chile en Santos (Nicolás López, 2008), con Argentina en Zenitram (Luis Barone, 2010) o con Colombia en Órbita 9 (Hatem Khraiche Ruiz-Zorrilla, 2017). En algunos casos la coproducción ha 
obligado a llevar a cabo rodajes en inglés como sucede en La posibilidad de una isla o en Autómata. En otros, forma parte de la estrategia para una comercialización más amplia de la película, como en Strandeed: náufragos.

Tradicionalmente la estrategia de la coproducción ha sido muy practicada con la intención de vender con mayor facilidad un mismo producto cinematográfico en los distintos países participantes. En el ámbito de la ciencia ficción, sin embargo, la pátina internacional de los filmes ha servido también para superar ciertos prejuicios en torno a la capacidad del cine español para producir películas solventes dentro del género. Entre otras cuestiones por la necesidad de amplios presupuestos en aquellas historias que han requerido de la realización de efectos especiales; pero también por la asunción de que una ciencia ficción "a la española" no era creíble para el público. En este sentido, resulta significativo el esfuerzo de algunas iniciativas por producir un cine fantástico y de ciencia ficción en España sin que el resultado pareciera en absoluto español para poder ser rentabilizado dentro y fuera de España.

Este fue el objetivo de la Fantastic Factory, que Filmax puso en marcha en 1999 para producir cine fantástico y que explicitaba, precisamente, esa intención de evitar cualquier tipo de seña de identidad nacional en sus películas "buscando fundirse y confundirse con un estilo internacional, de clara inspiración hollywoodiense, que atraiga al espectador al cine de forma indiferenciada, evitando el prejuicio, tan profundamente arraigado entre nuestro público, de huir de cualquier película española de género" (Palacios, 2006, p. 154). La estrategia era clara: si el cine más rentable era el estadounidense, había que producir películas que el público no pudiera diferenciar de aquellas. Una cuestión problemática, y a la vez sugerente, sobre la que llama la atención Andrew Willis con respecto a la Fantastic Factory, es "the problems of defining a "Spanish" film when looking at a production company that shows a continued commitment to making their films in English" (Willis, 2008, p. 27). Y no solo rodadas en inglés, sino con un reparto internacional y sin referencias geográficas o culturales que remitieran al contexto nacional y basadas en fórmulas y temas estandarizados propios de los géneros cinematográficos. 
Este proceder, sin embargo, no era exclusivo de la Fantastic Factory. Muchos productores/as y directores/as han acudido a estrategias de este tipo en diferentes momentos, así como al rodaje de las películas fuera del territorio español, una práctica más común en el caso de las coproducciones internacionales y más frecuente en las últimas décadas. Ejemplo paradigmático de ello sería Autómata, rodada en inglés en coproducción con Bulgaria y protagonizada por intérpretes como la danesa Birgitte Hjort Sørensen o las estrellas hollywoodienses Antonio Banderas y Melanie Griffith.

De entre las películas nacidas de la Fantastic Factory, algunas de ellas se aproximaron a la ciencia ficción. La primera fue Arachnid, dirigida por Jack Sholder y estrenada el mismo año que Parque Jurásico III (Joe Johnston, 2001), cuenta cómo una expedición científica acaba atrapada en una isla tras estrellarse su avioneta. Allí, los/las protagonistas deberán enfrentarse a unas gigantescas arañas mutantes, de procedencia extraterrestre. La segunda fue Beyond Re-Animator (Brian Yuzna, 2003), perteneciente a una saga que incluye Re-Animator (Stuart Gordon, 1985) y La novia de Re-animator (Brian Yuzna, 1990). Presenta una historia en la que el Dr. Herber West, lleva a cabo experimentos de reanimación que ya no sólo resucitan a los muertos, sino que además trata de devolverles el comportamiento racional para evitar su confusión y violencia. El descontrol de los experimentos, que se han llevado a cabo en la cárcel donde estaba prisionero el Dr. Herber, acaba en un desastroso motín. Destaca en estas películas el predominante tono de terror, línea que siguieron otros filmes cercanos a la ciencia ficción realizados fuera de la Fantastic Factory: Mucha Sangre (Pepe de las Heras, 2003) o Sexykiller, morirás por ella (Miguel Martí, 2008).

Aunque las primeras intenciones de la Fantastic Factory manifestaban su intención de facturar productos desnacionalizados que pudieran venderse en el mercado internacional, pronto tuvieron que abandonar esa estrategia para introducir elementos que, tímidamente, delataran la idiosincrasia española, lo que, al menos en el campo de la ciencia ficción, se ratifica en no pocos aspectos (Sánchez Trigos, 2018, p. 319). Entre otras cosas, algunas de las películas 
estaban protagonizadas por actores y actrices españoles reconocibles para el espectador, como José Sancho o Neus Asensi en Arachnid; y Santiago Segura en Beyond Re-Animator. Precisamente Beyond Re-Animator había sido un intento de conjugar "la vertiente española de la factoría y la americana" (Sala, 2010, p. 266). En este sentido, el cine de la Fantastic Factory se encuadra en las mismas características generales que el resto del cine español del momento, marcado por lo que parece una inevitable combinación de elementos globales y nacionales.

Con respecto a la cuestión autoral, hemos comentado ya los casos de Alex de la Iglesia y Alejandro Amenábar, cineastas que no por haber practicado el cine de géneros a lo largo de sus carreras han dejado de ser considerados bajo la idea de "autor" a la que nos referimos al inicio. En esta misma línea se encuentran otras figuras cuyas películas de géneros como la ciencia ficción no han ido en detrimento del reconocimiento de una personalidad creativa verdaderamente perceptible, valorada tanto por el público como por la crítica. Así sucede, por ejemplo, con Nacho Vigalondo en Cronocrímenes o Extraterrestre. Precisamente tras el estreno de Extraterrestre podía leerse en el periódico $A B C$ del 13 de octubre de 2011, la afirmación de que el director "Desde las primeras imágenes consiguió que comulgaran juntos prensa y público" (p.55). Otro caso notable es la incursión de Almodóvar en el género con La piel que habito, un cineasta que nadie duda en reconocer como uno de los grandes autores del cine español. En la película, el protagonista es una suerte de científico loco que utiliza sus conocimientos de cirugía y transgénesis para experimentar con su víctima. Un filme inspirado en la novela Tarántula (Thierry Jonquet, 1984), que inevitablemente recuerda a Los ojos sin rostro (Les yeux san visage, Georges Franju, 1960) y que tiene como antecedente otro ejemplo español en Gritos en la noche (Jesús Franco, 1962). Igualmente apreciada es la obra de Isabel Coixet, que dirigió para Gas Natural Fenosa una película futurista enfocada en el progreso tecnológico y la eficiencia energética, Proyecto tiempo (2018). 
Finalmente, por citar otros directores ampliamente reconocidos como autores de rabiosa originalidad, inimitables por su personalidad e incluso experimentación formal y narrativa; mencionamos a dos directores consolidados con anterioridad a la década de 1990 pero que, en los últimos años plantearon también proyectos de ciencia ficción. Nos referimos a José Luis Cuerda y Bigas Luna. El primero dio vida a una distopía de tono surrealista ambientada en el año 9177 en Tiempo después (2018), donde toma elementos recurrentes del género como el rascacielos al que el paso el tiempo ha convertido casi en ruina en mitad de un desierto. El segundo, dejó sin acabar el proyecto de Segundo Origen, que se encargó de dirigir, tras el fallecimiento de Bigas Luna, Carles Porta y que se estrenó en 2016. Una distopía apocalíptica de tintes ecológicos ambientada en Cataluña.

\section{Extraterrestres, sociedades distópicas y experimentos tecnocientíficos: principales temas y modelos}

Una vez expuestas las cuestiones relativas a la autoría, producción y transnacionalidad de las películas, pasamos a exponer la presencia que en el cine español han tenido los principales ejes temáticos de la ciencia ficción a nivel internacional. Como se podrá comprobar, los ejemplos españoles miran a referentes de éxito mundial y, a lo largo de las décadas, se han adentrado en asuntos tan variados como la inteligencia artificial, las invasiones extraterrestres, las distopías postapocalípticas o la experimentación genética. Observando el caso estadounidense (por ser el más influyente), se puede indicar que el progresivo perfeccionamiento de los efectos digitales ha convertido al último cine de ciencia ficción en pasto de alegorías sobre realidades virtuales, totalitarismos internautas e identidades fragmentadas (Sánchez, 2007). La industria española tratará de mimetizarse con las corrientes internacionales, abordando estos y otros temas que ya habían sido tratados en décadas anteriores por la cinematografía estadounidense, pero que no habían aparecido aún en la filmografía española o, si lo habían hecho, adquieren ahora una cierta madurez y mejoría en su factura. Un ejemplo es el 
de las historias de catástrofes, que, más allá de los desastres nucleares de la década de $1970^{8}$, inspirados en por la edad de oro del género, se aproxima ahora a referentes más recientes como Armaguedon (Michael Bay, 1998) o Deep Impact (Mimi Leder, 1998) con las producciones Tres días y Los últimos días. Tres días plantea la llegada de un meteorito que amenaza con destruir la Tierra al cabo de tres días, sin embargo, este acontecimiento no es más que una ambientación general que motiva el caos entre los habitantes del pueblo donde se desarrolla el argumento dando pie a que los presos escapen de la cárcel. Uno de ellos, se dispone a matar a la familia de Alejandro -el protagonista - tratando de terminar lo que había dejado pendiente cuando fue apresado. A partir de ese momento la película se desarrolla en torno al conflicto familiar, que desata la lucha entre el asesino y Alejandro, dispuesto a todo para salvar a sus cuatro sobrinos. En este sentido podemos emparentar la película con La hora incógnita (Mariano Ozores, 1963), de similar planteamiento. Por su parte, Los últimos días, se ambienta en una Barcelona postapocalíptica en la que toda la población sufre agorafobia, por lo que la población queda recluida en el interior de los edificios o en infraestructuras subterráneas como las estaciones de metro.

Un caso similar es el de La hora fría, del canario Elio Quiroga (2006), que plantea un futuro postapocalíptico en el que los/las protagonistas viven refugiados en un búnker y tienen que enfrentarse a un ejército de seres extraños, víctimas de una infección provocada por una gran guerra entre una mitad del mundo y otra, enfrentadas por motivos religiosos. La infección convierte a las personas en monstruos que, al ser ejecutados no desaparecen, sino que se convierten en seres invisibles capaces de reducir la temperatura a niveles insoportables con su mera presencia, causando la muerte a todo el que se acerca. La película parece recurrir a influencias más o menos claras del cine americano: John Carpenter, James Cameron o George A. Romero; aunque asimilándolas de un modo personal (Conde y Mérida, 2008, p. 269).

${ }^{8}$ El refugio del miedo (José Ulloa, 1974), Último deseo (León Klimovsky, 1976) o Espectro. Más allá del fin del mundo (Manuel Esteba, 1978). 
Otro de los temas recurrentes de la ciencia ficción a partir de la década de 1980 había sido el de la experimentación genética en busca de la perfección física del ser humano. El cine español ya venía mostrando algún ejemplo al respecto en filmes como El vivo Retrato, El niño de la Luna (Agustí Villaronga, 1989) o La mujer más fea del mundo. Otra película en la primera década de los 2000 es la coproducción hispanofrancesa La posibilidad de una isla, adaptación de la novela homónima que dirige su mismo autor, Michael Houellebecq y que se estrena en 2009. La historia plantea la posibilidad de lograr la inmortalidad a través de diversos experimentos que incluyen la clonación y la descarga de la mente a un ordenador. Sin embargo, es con la ya citada La piel que habito que el tema de intervención genética adquiere la densidad que ya habían demostrado tiempo atrás películas como Gattaca (Andrew Niccol, 1997). Robert Legard, un prestigioso cirujano plástico que intentó reconstruir, por medio de experimentos de transgénesis en los que modifica piel humana con células de cerdo, el rostro desfigurado de su mujer. Tras el suicidio de ésta y de su hija, que había sido violada en una fiesta, Robert queda traumatizado y comienza su sofisticada venganza hacia el violador de su hija, al que utiliza como cobaya de sus experimentos para desarrollar la piel más resistente del mundo; y al que acaba transformando en una mujer que replica el rostro y cuerpo de su esposa.

En cuanto al asunto extraterrestre, presente en toda la historia del género, hay que destacar el caso de Stranded: Náufragos de María Lidón, que sobresale por ser, hasta el momento, la única película de ciencia ficción producida en España dirigida por una mujer (ya hemos citado el caso posterior de Isabel Coixet con Proyecto Tiempo)9. Además, es de las pocas guionizadas por un escritor de ciencia ficción, Juan Miguel Aguilera. La película se estrenó un año después que Misión a Marte (Mission to Mars, Brian de Palma, 2000) y Planeta Rojo (Red Planet, Anthony Hoffman, 2000); “quien sabe si ha sido por esta razón, pero lo cierto es que Náufragos terminó por ser una de las tres películas que mejor retrató un hipotético viaje a Marte" (Rodríguez, 2007, p.

9 Existen ya necesarias aportaciones en castellano a una relectura feminista de la ciencia ficción (McCausland y Salgado, 2019). 
357). Para ello, las secuencias del planeta fueron rodadas en los volcánicos paisajes de la isla de Lanzarote, que aportan el ambiente desértico y hostil que requería el filme. La historia cuenta cómo la tripulación de una misión a Marte debe sobrevivir en el planeta tras haberse estrellado su nave. Para aprovechar los recursos de los que disponen mientras llega el posible rescate, deciden que sólo dos de ellos/as podrían sobrevivir. El giro argumental se produce cuando la tripulación descubre una red de túneles construida por una antigua civilización marciana ya extinguida que conduce a una zona del planeta en la que la presión del aire y la cantidad de oxígeno son suficientes para sobrevivir. La original trama, el reparto foráneo, el rodaje en inglés y el buen acabado técnico, son las armas con las que el filme trató de introducirse en el mercado internacional; sin embargo, la película más bien "gozó de un estreno discreto, sobre todo teniendo en cuenta su abultado presupuesto" (Sánchez Trigos, 2018, p. 320).

Otra película que aborda el tema alienígena - esta vez una invasión- es Extraterrestre. Ambientada en una Madrid completamente evacuada tras la aparición de unos gigantescos OVNIS que están sobrevolando numerosas ciudades españolas. Los/as cuatro protagonistas son los únicos que han permanecido en la ciudad y la historia que se va a desarrollar tiene más que ver con la relación que existe y que se va a dar entre ellos/as, que con un verdadero enfrentamiento con los extraterrestres. En esta película, de nuevo, el marco de ciencia ficción sirve como telón de fondo para generar el ambiente dramático que provoca la tensión entre los personajes e intensifica sus emociones; un recurso que posibilita la reducción de unos efectos especiales bastante solventes y que no obliga a recurrir a un presupuesto excesivo.

Durante este periodo aparecen también algunos filmes de animación: Goomer (José Luis Feito y Carlos Varela, 1999), P3K: Pinocho 300o, Cristóbal Molón (Íñigo Berasategui, Aitor Arregui, 2006) y Planet 51. Goomer está protagonizada por un camionero intergaláctico que se ve en la obligación de realizar un aterrizaje forzoso en un planeta habitado, en el que tratará de saltar a la fama tras caer, precisamente en la fiesta de un famoso director de cine. 
P3K: Pinocho 30oo, es una versión del clásico personaje de Pinocho, en la que el protagonista es un robot que tiene la personalidad de un niño desde convertirse en uno de carne y hueso. Por su parte, Cristóbal Molón, narra las fechorías de Destruzzio, consejero del Rey Pinzón II de Pradeira, con motivo de una expedición a la Luna para esculpir en ella la cara del rey. Finalmente, Planet 51, plantea la historia de una familia de extraterrestres tras la llegada a su planeta de un alienígena humano, un astronauta americano que creía ser el primero en pisar el planeta. La película recrea el ambiente estadounidense de los años cincuenta, cuando el temor a una invasión extraterrestre estaba a la orden del día.

En otra dirección estarían Somne, Los cronocrímenes y Eva; películas que se cuestionan no tanto las consecuencias que traen para el mundo las malas relaciones humanas (al modo de lo sucedido en La hora fría) como las que pueden derivarse de un exceso o un uso cuestionable del desarrollo científico y tecnológico. Esta concepción de los avances de la ciencia se une a la interpretación tecnofóbica que tuvo su auge en el cine estadounidense desde los años ochenta y más especialmente a partir de la década de los noventa; con películas que a la vez que celebran el poderío tecnológico del ser humano, advierten de las dificultades y peligros a los que se enfrenta al forjar una cultura y humanidad predominantemente tecnológicas (Telotte, 2002, p. 130).

Somne cuenta la historia de Andrea, una joven y brillante neuróloga que decide volver a la universidad donde estudió para desarrollar un experimento que permita encontrar la forma de transmitir información desde un ordenador al cerebro humano aprovechando ciertos estados que se generan durante el sueño. Fallecida su predecesora en extrañas circunstancias, la protagonista advierte, junto a los miembros de su equipo (Gabriel, un genio de la informática con el que mantuvo un romance en el pasado, y Diego, un especialista en trastornos del sueño) los peligros que puede suponer el proyecto si cae en manos equivocadas. A medida que avanza en sus investigaciones, Andrea sufre una serie de pesadillas en las que se comunica con un misterioso joven, que la llevará a descubrir los oscuros propósitos con 
los que se había iniciado el proyecto. La integración cibernética entre el ser humano y las máquinas señala, en este caso, los riesgos que entrañan los nuevos avances científicos y la falta de escrúpulos de las grandes empresas a la hora de hacer experimentos con humanos. Por su parte, Los cronocrímenes, se adentra en una historia de viaje a través del tiempo en la que se incide en el deseo humano de retroceder para poder deshacer los hechos del pasado. El protagonista es Héctor, un hombre que, tras observar a una extraña joven con los prismáticos desde el jardín de su casa, se adentra en el bosque para tratar de encontrarla. Allí, es sorprendido por un extraño personaje con la cabeza vendada que lo ataca y le obliga a refugiarse en un complejo científico, donde acaba siendo víctima de un experimento de viaje en el tiempo.

Finalizada ya la primera década del siglo XXI, se estrena un filme que destaca por su acabado técnico, con unos efectos especiales que se manifiestan a lo largo de todo el filme; y también por la temática explorada, inédita hasta entonces en la producción española: Eva. La película, a pesar de ser el primer largometraje español que trata directamente el asunto de la inteligencia artificial, no se conforma con plantear y explotar las posibilidades de creación de máquinas inteligentes, sino que se sitúa en los conflictos más sofisticados de esta vertiente del género, como es la preocupación y las consecuencias que puede acarrear la creación de un ser artificial dotado de emociones. En este sentido, la película de Kike Maíllo se acerca a las reflexiones planteadas por otros filmes de referencia como Blade Runner (Ridley Scott, 1982) o Inteligencia Artificial (A. I.: Artificial Intelligence, Spielberg, 2001). El filme plantea la creación de un niño robot social, capaz de empatizar con sentimientos humanos. Alex, el protagonista, será el encargado de realizar este trabajo, para lo que regresa a su ciudad natal, Santa Irene, donde se reencuentra con su hermano, actualmente casado con Lana, de la que Alex siempre había estado enamorado. El matrimonio tiene una hija, Eva, que a lo largo de la trama se descubre que es precisamente una inteligencia artificial. Cuando Eva lo descubre, su desequilibrio emocional acaba propiciando un accidente en el que Lana muere. En este punto, se reaviva la polémica sobre la inseguridad que puede conllevar la creación de robots dotados de un software 
emocional, motivo por el cual se había abandonado el proyecto diez años antes. Llama la atención el acabado de los efectos especiales, que en este caso no se relega a una trama secundaria o un escenario concreto de la película; sino que convive plano a plano con el drama de los personajes. Así, los robots (creados mediante maquetas reales y digitales y efectos con pantallas verdes) transitan constantemente las calles, son instrumento de trabajo en la universidad, e incluso se convive con ellos-. Además, el despliegue de efectos está presente también en la sofisticada tecnología que configura el cerebro del robot en el que trabaja el protagonista, uno de los elementos fundamentales de la historia. En este sentido, el valor que adquiere una película como Eva en el contexto de la ciencia ficción producida en España, tiene que ver con la superación de ciertos desconfianzas existentes en la industria cinematográfica nacional, que, salvando algunas excepciones a lo largo de su historia - como los logros de Juan Piquer Simón (Lizcano y Garcicuño, 2014)-, ha sido poco capaz, por escasez de presupuestos, de lograr unos resultados técnicos y unos efectos especiales que estuvieran a la altura de las exigencias de un público acostumbrado al espectáculo visual de las películas estadounidenses.

No quisiéramos dejar de señalar, además de las novedades temáticas y visuales, la realización de filmes a partir de estrategias de producción alternativas que se han dado en los últimos tiempos, como el crowfunding o micromecenazgo, sistema de financiación colectiva que posibilita que proyectos que no reciben el apoyo de instituciones o grandes inversiones privadas, puedan ver la luz. Es el caso de El cosmonauta (Nicolás Alcalá, 2013), que presumió de ser la primera película española financiada mediante esta estrategia, con hasta 5000 aportaciones económicas distintas. Narra la historia de un astronauta ruso desaparecido tras ser enviado a la Luna en 1975. Pese a darse por desaparecido, el cosmonauta se comunica a través de mensajes de radio, afirmando que ha regresado a la Tierra, pero que la ha encontrado vacía.

Un año después, multiplicando la inversión en producción y la presencia de efectos especiales de la que ya podía presumir Eva, se estrena, en 2014 
Autómata. La película se ambienta en el año 2044, cuando el aumento de tormentas solares ha convertido el planeta Tierra en un terreno radiactivo hostil para el ser humano, que se refugia en ciudades amuralladas. En este contexto, Jacq Vaugan, un agente de seguros de una empresa de robótica, investiga el caso de unos robots que parecen tener la capacidad de auto repararse, violando los protocolos de seguridad de la compañía. La película, protagonizada por Antonio Banderas, continúa teniendo como referencia principal el modelo de Blade Runner, aunque termina desarrollando algunas cuestiones novedosas en cuanto al planteamiento filosófico de la posible evolución de las máquinas inteligentes y su relación con la especie humana en el futuro. Las experimentaciones tecnocientíficas han seguido siendo protagonistas en filmes como Proyecto Lázaro (Mateo Gil, 2016), cuyo protagonista es reanimado tras someterse a un proceso de criónica; o En tu cabeza (Daniel Sánchez Arévalo, Kike Maíllo, Borja Cobeaga y Alberto Ruiz Rojo, 2016), cuya protagonista, proveniente del futuro, se dedica a adentrarse, gracias a una novedosa tecnología, en las cabezas de los ciudadanos y ciudadanas del presente con el fin de concienciarlos para llevar una vida sostenible y salvar el futuro del planeta.

Por último, quisiéramos señalar el auge que en los últimos años han tenido en el cine español las películas distópicas. Tal y como ha señalado ya Diana Palardy (2018), el impacto en España de la crisis económica de 2008 ha suscitado el aumento de obras apocalípticas o ambientadas en futuros distópicos, especialmente en el ámbito literario pero también en el cine. La incertidumbre ante el futuro, las desigualdades sociales y la precariedad económica han sido el caldo de cultivo sobre el que se han cocinado numerosas distopías y apocalipsis en los últimos años: Los últimos días, L’Altra Frontera, Sueñan los androides (Ian de Sosa, 2014), Extintion (Miguel Ángel Vivas, 2015), Evolution, Vulcania (José Skaf, 2015), Segundo Origen o El hoyo (Galder Gaztelu-Urrutia, 2019). 


\section{Conclusiones}

En conclusión, podemos afirmar que, aunque, efectivamente, la ciencia ficción ha sido un género mucho menos practicado que otros en nuestro país, tampoco puede afirmarse que ha estado ausente en la cinematografía española a lo largo de su historia. Además, se ha constatado cómo su producción ha ido en aumento en las últimas décadas. Así mismo, se comprueba que el cine español no ha dejado de acercarse a cada una de las grandes fascinaciones que la ciencia ficción ha explorado a lo largo de su historia, desde los viajes temporales o visitas extraterrestres, hasta la experimentación tecnocientífica o la inteligencia artificial, pasando por las distopías y los futuros apocalípticos. En lo que respecta al periodo que se inicia en la última década del siglo XX y se extiende en las primeras del XXI, destacamos la progresiva normalización de la presencia de la ciencia ficción en el cine español. Ello se debe, en buena medida, a la renovación de referencias e hibridación narrativa a partir de la generación de los noventa; pero también la necesidad de internacionalización de los proyectos, que obliga a plantear historias de éxito transnacional, para lo cual los géneros cinematográficos y las estrategias de coproducción son grandes aliados. En esta línea, hemos señalado cómo en algunos casos se recurre a equipos internacionales, rodajes en inglés o historias deslocalizadas: Atolladero, Stranded: náufragos, Eva, Autómata, Extintion o Proyecto Lázaro. No obstante, otros muchos ejemplos denotan también el interés por la creación de filmes de ciencia ficción con señas de identidad nacional o local: Acción Mutante, El milagro de P tinto, Extraterrestre, La piel que habito, Los últimos días, L'altra frontera o Segundo Origen.

Finalmente, del mismo modo que ha sucedido a través de la práctica de otros géneros narrativos, la ciencia ficción ha formado parte de una progresiva difuminación de la dicotomía entre cine autoral y cine comercial que tradicionalmente ha marcado a la crítica y a la percepción del público. Cineastas con un evidente interés por el cine de géneros como Álex de la Iglesia, Amenábar o Vigalondo han sido reconocidos y valorados por su personalidad creativa y sus estilos propios de un modo que quizás hubiera sido 
imposible en generaciones anteriores a la década de 1990. Igualmente, cineastas consolidados como autores con anterioridad, no han mostrado prejuicios al acercarse a este y otros géneros cinematográficos, como muestran las filmografías de Almodóvar o Bigas Luna.

\section{Referencias bibliográficas}

Altman, R., (2000), Los géneros cinematográficos, Barcelona: Paidós.

Angulo, J. y Santamarina, A., (2012), Álex de la Iglesia: la pasión de rodar, San Sebastián: Fundación Filmoteca Vasca.

Beck, J., y Rodríguez Ortega, V. (Eds.), (2008), Contemporary Spanish cinema and genre, Manchester: Manchester University Press.

Benet, V. J., (2012), El cine español. Una historia cultural, Barcelona: Paidós.

Berthier, N. (dir.), (2007), Le cinéma d'Alejandro Amenábar, Toulousse: Presses Universitaires du Mirail.

Buse, P., Triana-Toribio, N. y Willis, A. (2007), The cinema of Álex de la Iglesia, Manchester: Manchester University Press.

Camporesi, V., (2011), Panorama de la cinematografía española en el periodo 1990-2008. En Vargas, J. C., (Coord.), Tendencias del cine iberoamericano en el nuevo milenio. Argentina, Brasil, España y México, (pp. 73-94). Guadalajara: Universidad de Guadalajara.

Conde, P. y Mérida P. J. (2008), Cine bizarro y fantástico hispano-argentino entre dos siglos, Málaga: Semana Internacional de Cine Fantástico y de Terror de Estepona y Ayuntamiento de Estepona.

Heredero, C. F., (1997), Espejo de miradas. Entrevistas con nuevos directores del cine español de los años noventa. Madrid: 27 Festival de Cine de Alcalá de Henares.

Heredero, C. F., (1993), Las huellas del tiempo. Cine español 1951-1961, Valencia: Filmoteca de la Generalitat Valenciana/Filmoteca Española.

Huerta, M. Á., (2005), Los géneros cinematográficos: usos en el cine español (1994-1999), Salamanca: Universidad Pontificia de Salamanca.

Kinder, Marsha (1993), Blood Cinema: The Reconstruction of National Identity in Spain, Berkley y Los Angeles: University of California Press.

Labanyi, J. y Pavlović, T., (2013), A Companion to Spanish Cinema, Oxford: Wiley-Blackwell.

Lizcano, D. y Garcicuño, A., (2014), Los alquimistas del $7^{0}$ arte. Efectos especiales en el cine español, Bilbao: Area51. 
Madrid, D., (2019), La humanidad en peligro: alteraciones y suplantaciones del ser humano en el cine español (1992-2014), Tesis doctoral dirigida por Valeria Camporesi, Universidad Autónoma de Madrid.

McCausland, E. y Salgado, D., (2019), Supernovas: una historia feminista de la ciencia ficción audiovisual, Errata Naturae Editores.

Monterde, J. E., (2006), Cuando el destino nos alcance. Contextos del último cine español. En Rodríguez, H. J., (Coord.), Miradas para un nuevo milenio. Fragmentos para una historia futura del cine español, (pp. 53-62). Madrid: 36 Festival de Cine Alcalá de Henares-Comunidad de Madrid.

Monterde, J. E., (1995), El cine de la autarquía (1993-1950). En VV.AA, Historia del cine español, (pp.181-238). Madrid: Cátedra.

Oliete-Aldea, E. Oria, B. y Tarancón, J. A., (Eds.), (2016), Global Genres, Local Films. The Transnational Dimension of Spanish Cinema, Londres y Nueva York: Bloomsbury.

Palacios, J., (2006), Los últimos días de la bestia. Cine fantástico español ante el nuevo milenio. En: Rodríguez, H. J., (Coord.), Miradas para un nuevo milenio. Fragmentos para una historia futura del cine español, (pp.151-157). Madrid: 36 Festival de Cine de Alcalá de HenaresComunidad de Madrid.

Palardy, D. Q., (2018), The Dystopian Imagination in Contemporary Spanish Literature and Film, Cham, Switzerland: Palgrave Macmillan, Hispanic Urban Studies.

Pérez Morán, E. y Pérez Millán, J. A., (2017), Las políticas cinematográficas en los ochenta y noventa. En Sánchez Noriega, J. L., (Ed.), Trayectorias, ciclos y Miradas del cine español (1982-1998), (pp. 31-52). Barcelona: Laertes.

Pohl, B. y Türschmann, J. (Eds.), (2007), Miradas Glocales. Cine español en el cambio de milenio. Madrid, Iberoamericana-Vervuet.

Rodríguez Marchante, O. (2002), Amenábar, vocación de intriga, Madrid: Páginas de espuma.

Rodríguez Ortega, V., (2020), The Return of Genre in 1990s Spanish Cinema: Industry, Legislative Changes and Economics, Hispanic Research Journal, 21:1, 3-22, DOI: 10.1080/14682737.2019.1635376

Sala, A., (2010), Profanando el sueño de los muertos. La historia jamás contada del cine fantástico español, Pontevedra: Scifiworld.

Sánchez, S., (2007), Películas clave del cine de ciencia ficción, Barcelona: Ediciones Robinbook.

Sánchez Noriega, J. L., (Ed.), (2020), Cine español en la era digital: emergencias y encrucijadas, Barcelona: Laertes.

Sánchez Noriega, J. L., (Ed.), (2019), Imaginarios y figuras en el cine de la postransición, Barcelona: Laertes. 
Sánchez Trigos, R., (2018), Cine 1980-2015. En: López-Pellisa, T., (Ed.), Historia de la ciencia ficción en la cultura española, (pp. 301-326). Madrid y Frankfurt: Iberoamericana Vervuert.

Sempere, A. (2004), Amenábar, Amenábar, Alicante: Editorial Club Universitario.

Stam, Robert, (2001), Teorías del cine. Una introducción, Barcelona: Paidós.

Teotte, J. P., (2002), El cine de ciencia ficción, Madrid: Cambridge University Press.

Triana-Toribio, N., (2008), Auteurism and commerce in contemporary Spanish cinema: directores mediáticos, Screen, 49 (3), 259-276.

Willis, A., (2008), The Fantastic Factory: the horror genre and contemporary Spanish Cinema. En: Beck, J. y Rodríguez Ortega, V., (Eds.), Contemporary Spanish Cinema and Genre, (pp. 27-43). Manchester: Manchester University Press. 